\title{
DIVERSIDADE E ABUNDÂNCIA DE ARTRÓPODES PREDADORES ASSOCIADOS A DIFERENTES CULTIVARES DE ALGODOEIRO ${ }^{1}$
}

\author{
Lílian Lúcia Costa ${ }^{2}$, Ivan Carlos Fernandes Martins², Antonio Carlos Busoli², Francisco Jorge Cividanes ${ }^{2}$
}

\section{ABSTRACT \\ DIVERSITY AND ABUNDANCE OF PREDACEOUS ARTHROPODS ASSOCIATED WITH DIFFERENT COTTON CULTIVARS}

With the objective of studying the abundance and diversity of predaceous arthropods associated with cotton crop, and analyze the influence of meteorological factors, interactions between natural enemies and population dynamics of coccinellids associated with their principal prey, the aphid Aphis gossypii, an experiment was carried out in the region of Ipameri, Goiás State, Brazil, at the Universidade Estadual de Goiás campus. The experimental design was randomized blocks, with five treatments, consisting of the DeltaOPAL, FMX 966, FMX 993, FMX 910, and NuOPAL cultivars, in four replications. Among the arthropods sampled in the cotton crop, the coccinellids and spiders were the most abundant ones in the cultivars evaluated. Spiders occurred throughout the cotton cycle, while the coccinellids population increased gradually until $55 \mathrm{DAE}$, showing a population peak at $34 \mathrm{DAE}$, coinciding with the population peak of aphids (Aphis gossypii). Among the coccinellids observed in the cultivars under study, Scymnus spp. was the most abundant in cotton. The pentatomid and forficulid occurred from 99 to 128 days after the emergence of cotton, which corresponds to the highest density of target pest insects. It was not found influence of meteorological factors or negative interactions among predaceous arthropods.

KEY-WORDS: Gossypium hirsutum; natural enemies, coccinellids.

\section{INTRODUÇÃO}

O algodoeiro é considerado uma das culturas mais importantes do Brasil, quer pela multiplicidade dos produtos dele originados, quer pela posição de destaque no setor socioeconômico, uma vez que o País é o quinto maior produtor mundial de algodão e o sexto maior consumidor e exportador desta fibra (Conab 2009).

\section{RESUMO}

Com o objetivo de estudar a abundância e a diversidade de artrópodes predadores associados à cultura do algodoeiro e analisar a influência de fatores meteorológicos, interações entre inimigos naturais e a dinâmica populacional de coccinelídeos associados à sua principal presa, o pulgão Aphis gossypii, um experimento foi realizado na região de Ipameri (GO), no Campus da Universidade Estadual de Goiás. O delineamento experimental utilizado foi o de blocos ao acaso, com cinco tratamentos, constituídos pelas cultivares DeltaOPAL, FMX 966, FMX 993, FMX 910 e NuOPAL, em quatro repetições. Dentre os artrópodes observados na cultura do algodoeiro, os coccinelídeos e as aranhas foram os mais abundantes, nas cultivares avaliadas. As aranhas ocorreram em todo o ciclo do algodoeiro. Já os coccinelídeos aumentaram sua população, gradativamente, até $55 \mathrm{DAE}$, apresentando pico populacional aos $34 \mathrm{DAE}$, coincidindo com o pico populacional dos pulgões $A$. gossypii. Dentre os coccinelídeos observados nas cultivares em estudo, verificou-se que Scymnus spp. foi o gênero mais abundante no algodoeiro. Os pentatomídeos e forficulídeos predominaram dos 99 aos 128 dias após a emergência do algodão, período que corresponde à maior densidade de pragas-alvo destes insetos. Verificou-se que não houve influência dos fatores meteorológicos e nem interação negativa entre os artrópodes predadores.

PALAVRAS-CHAVE: Gossypium hirsutum; inimigos naturais; coccinelídeos.

Entre os diversos fatores que afetam o crescimento, desenvolvimento e a produtividade desta malvácea, destaca-se a ocorrência de insetos-praga, os quais atacam as mais variadas partes da planta, como raiz, caule, folhas, botões florais, flores, maçãs e capulhos (Busoli et al. 2006, Pereira et al. 2006), cujos danos podem reduzir a produtividade e afetar, diretamente, as sementes e a fibra, causando prejuízos na comercialização. 
De acordo com Freire et al. (1999), verificam-se altos custos na produção de algodão, nas regiões de Cerrado, e os investimentos realizados, para controle de pragas na cultura do algodoeiro, correspondem a 25-30\% do total do custo de produção, fato, este, que confere ao manejo de pragas um componente significativo na rentabilidade da cultura e fator preponderante para a obtenção de lucros na atividade.

Apesar do conhecimento de várias alternativas de controle, recomendadas nos programas de manejo integrado de pragas, a maioria dos sistemas de produção de algodão no mundo é dependente do uso de inseticidas, que se destaca como a principal medida de controle de pragas (Degrande et al. 2003). Contudo, entre o complexo de artrópodes associados à cultura do algodoeiro, além das pragas que causam danos à cultura, também há os inimigos naturais, sendo a maioria predadores e parasitóides de espécies fitófagas (Lutrell et al. 1994), que desempenham papel importante no controle natural das populações de pragas (Silvie et al. 2001).

Os predadores são considerados, entre os inimigos naturais, a primeira linha de defesa contra insetos fitófagos, na cultura do algodoeiro. Entre os fatores que podem influenciar sua ocorrência, destacam-se a abundância e a qualidade das presas (Oliveira et al. 2001, Oliveira et al. 2002); a utilização de áreas adjacentes, como áreas de refúgio (Prasifka et al. 1999); e as interações entre predadores generalistas (Cisneros \& Rosenheim 1997). A abundância e eficiência de predadores também podem variar consideravelmente, de ano para ano e de região para região (Gravena \& Sterling 1983).

Dentre os predadores de ocorrência mais comum, relacionados com o controle de pragas na cultura do algodoeiro, destacam-se os gêneros Solenopsis (Hymenoptera: Formicidae); Chrysoperla (Neuroptera: Chrysopidae); os hemípteros dos gêneros Geocoris (Lygaeidae), Nabis (Nabidae), Zelus (Reduviidae) e Podisus (Pentatomidae); Cycloneda, Scymnus, Eriopis, Coleomegilla, Harmonia, Hippodamia e Diomus (Coleoptera: Coccinellidae), além de diversas espécies de aranhas (Gravena \& Cunha 1991, Fitt 1994, Luttrell et al. 1994).

Como exemplo do potencial de predação de alguns destes organismos, pode-se citar a espécie Chrysoperla externa, cujo consumo médio pode chegar a 846,85 pulgões Aphis gossypii (Hemiptera: Aphididae) e 253,20 ninfas de mosca-branca (Bemisia argentifolii) (Hemiptera: Aleyrodidae), durante seu ciclo de vida (Costa et al. 1999). Já os adultos de Podisus nigrispinus podem predar, em média, 1,9 lagarta pequena de Alabama argillacea (Lepidoptera: Noctuidae) por dia, em condições de laboratório (Oliveira et al. 2001).

A família Coccinellidae destaca-se por possuir muitas espécies que são consideradas excelentes agentes de controle biológico de pragas agrícolas (Obrycki \& Kring 1998, Iperti 1999), devido à sua habilidade de se alimentar de diferentes tipos de presas. Além disto, tais insetos apresentam várias características desejáveis, como predadores, visto que se encontram em todos os ambientes de suas presas, têm grande capacidade de busca por alimentos e são extremamente vorazes (Oliveira et al. 2005, Sarmento et al. 2007).

De acordo com Alves \& Serikawa (2006), a preservação de inimigos naturais, na cultura do algodoeiro, é imprescindível para a regulação natural de populações de insetos-praga. Assim, é extremamente necessário definir meios práticos e eficientes no controle de pragas, de forma a provocar a menor alteração possível no meio ambiente e a manutenção da população de insetos benéficos. Segundo Fernandes et al. (2003), o manejo integrado de pragas (MIP) tem sido indicado como excelente método para se atingir tal objetivo.

Para o manejo da população de artrópodes que se inter-relacionam no agroecossistema algodoeiro, são necessários estudos sobre a diversidade de espécies e a dinâmica populacional de inimigos naturais e suas presas. Com base no exposto, os objetivos do presente trabalho foram estudar a abundância e diversidade de artrópodes predadores associados a diferentes variedades de algodoeiro, a influência de fatores meteorológicos na ocorrência dos mesmos, as possíveis interações entre inimigos naturais e, ainda, verificar a dinâmica populacional de coccinelídeos associados à sua principal presa, o pulgão $A$. gossypii, na região de Ipameri, GO.

\section{MATERIAL E MÉTODOS}

O experimento foi conduzido de dezembro de 2007 a abril de 2008, na área experimental da Universidade Estadual de Goiás (UEG), localizada no município de Ipameri, GO (1743’19’'S, 4809’35’'W e altitude de $764 \mathrm{~m}$ ).

O delineamento experimental utilizado foi o de blocos ao acaso, com cinco tratamentos, constituídos pelas cultivares convencionais DeltaOPAL, 
FMX 966, FMX 993, FMX 910 e a transgênica NuOPAL, em quatro repetições. Cada parcela foi constituída de área de $54 \mathrm{~m}^{2}$, compreendendo seis linhas de plantas, com 10 metros de comprimento, espaçadas em 0,9 m entre si, utilizando-se uma densidade de dez plantas por metro linear.

O controle das plantas daninhas foi realizado através de capinas e a adubação de plantio e de cobertura foram realizadas de acordo com a análise de solo, seguindo-se as recomendações de Sousa \& Lobato (2004). Não foi aplicado inseticida neste experimento, para não afetar a população dos artrópodes em estudo.

Aos 60, 70 e 80 dias após a emergência(DAE), devido à frequência de chuvas e umidade relativa do ar em torno de $80 \%$, aplicou-se fungicida à base de benzimidazol e triazol, na dosagem de $800 \mathrm{~mL} \mathrm{ha}^{-1}$, para controlar o desenvolvimento de Ramulária (Ramularia areola), e, aos 45 DAE, utilizou-se o regulador de crescimento vegetal $\mathrm{Pix}^{\circledR}$ (Cloreto de mepiquat), na dosagem de $1,0 \mathrm{~L} \mathrm{ha}^{-1}$.

As avaliações foram realizadas semanalmente, a partir do nono dia após a emergência (DAE), e estenderam-se até os $128 \mathrm{DAE}$, totalizando 17 observações. Foram examinadas, visualmente e ao acaso, cinco plantas inteiras por parcela, totalizando 20 plantas por cultivar, em cada avaliação, e 340 plantas no ciclo do algodoeiro. Para contabilizar o número de predadores e pulgões presentes nas amostragens, durante o ciclo da cultura do algodoeiro, o total de 1.700 plantas foi observado, em todo o período, sendo avaliadas 100 plantas por amostragem.

Os predadores presentes nas amostragens foram separados por famílias, com exceção das aranhas, que foram agrupadas na ordem Araneae. $\mathrm{O}$ levantamento populacional de $A$. gossypii foi realizado juntamente com as avaliações realizadas para os predadores. Exemplares dos artrópodes foram separados e encaminhados para laboratório, para posterior identificação.

Os Coccinellidae foram identificados em nível de espécie ou gênero e sua ocorrência foi analisada separadamente. Para as formas imaturas, o único gênero identificado foi Scymnus spp.

Foi avaliada, também, a interação entre os artrópodes predadores e a influência de fatores meteorológicos sobre a ocorrência da população de predadores, através da análise de correlação linear simples, a 5\% de significância. Os fatores meteorológicos considerados foram as temperaturas máxima e mínima $\left({ }^{\circ} \mathrm{C}\right)$ e a precipitação pluvial $(\mathrm{mm})$. Os registros dos fatores meteorológicos foram obtidos junto à Estação Agroclimatológica de Ipameri, GO. As temperaturas foram representadas pela média da semana, enquanto, para a precipitação pluvial, foi considerada a soma semanal registrada.

A abundância de predadores entre as cultivares foi avaliada considerando-se o número médio de predadores encontrados nas 17 avaliações (20 plantas observadas por cultivar). Os dados da abundância de artrópodes predadores obtidos foram submetidos a análise de variância e as médias dos tratamentos comparadas pelo teste Tukey, a 5\% de significância, utilizando-se o programa ESTAT. Na análise de comparação da abundância de famílias de artrópodes entre as cultivares, os dados foram transformados em $\log (x+5)$.

\section{RESULTADOS E DISCUSSÃO}

Abundância de artrópodes predadores por cultivar

As cultivares FMX 993, FMX 910, DeltaOPAL e a transgênica NuOPAL apresentaram ocorrência semelhante de predadores na parte aérea, com total de 128, 101, 122 e 122 indivíduos por cultivar, respectivamente, em todo o período de amostragens (Tabela 1). Já a cultivar FMX 966 apresentou menor número de predadores, em relação às demais cultivares (83 exemplares). Em todas as cultivares, houve predominância de predadores da família Coccinellidae, exceto na cultivar FMX 966, onde houve maior predominância de aranhas (Tabela 1).

Eubanks \& Denno (2001) sugeriram que a maior ocorrência de predadores polífagos em uma área é influenciada pela maior ocorrência de presas com baixa mobilidade. O pulgão é uma praga estacionária, ou seja, de baixa mobilidade, sendo considerado presa fácil para os coccinelídeos. Desta forma, como na cultivar FMX 966 foi observada menor ocorrência de pulgões, é esperada menor ocorrência de coccinelídeos, quando comparada com as outras cultivares com maior densidade de pulgões (Figura 1 e Tabela 2).

Verificou-se, pelos dados obtidos da abundância de artrópodes predadores, que, apesar de as cultivares apresentarem totais de predadores distintos, houve diferença significativa apenas entre os coccinelídeos adultos, nas cultivares DeltaOPAL e FMX 966 (Tabela 2), provavelmente em função 
Tabela 1. Abundância absoluta e relativa de artrópodes predadores observados nas cultivares de algodoeiro, em todo o período de amostragens (Ipameri, GO, 2007/2008).

\begin{tabular}{|c|c|c|c|c|c|c|c|c|c|c|}
\hline \multirow{3}{*}{ Artrópodes } & \multicolumn{10}{|c|}{ Cultivares } \\
\hline & \multicolumn{2}{|c|}{ FMX 993} & \multicolumn{2}{|c|}{ FMX 910} & \multicolumn{2}{|c|}{ FMX 966} & \multicolumn{2}{|c|}{ NuOPAL } & \multicolumn{2}{|c|}{ DeltaOPAL } \\
\hline & $\mathrm{n}$ & $\%$ & $\mathrm{n}$ & $\%$ & $\mathrm{n}$ & $\%$ & $\mathrm{n}$ & $\%$ & $\mathrm{n}$ & $\%$ \\
\hline Araneae & 49 & 38,28 & 35 & 34,65 & 38 & 45,78 & 41 & 33,61 & 34 & 27,87 \\
\hline Coccinellidae (adulto) & 21 & 16,41 & 13 & 12,87 & 7 & 8,43 & 17 & 13,93 & 27 & 22,13 \\
\hline Coccinellidae (larva) & 42 & 32,81 & 37 & 36,64 & 19 & 22,89 & 41 & 33,61 & 39 & 31,97 \\
\hline Chrysopidae (larva) & 3 & 2,34 & 0 & 0,00 & 3 & 3,62 & 2 & 1,64 & 2 & 1,64 \\
\hline Forficulidae & 6 & 4,69 & 9 & 8,91 & 5 & 6,03 & 17 & 13,93 & 9 & 7,38 \\
\hline Pentatomidae & 7 & 5,47 & 6 & 5,94 & 6 & 7,23 & 0 & 0 & 3 & 2,46 \\
\hline Reduviidae & 0 & 0,00 & 1 & 0,99 & 5 & 6,02 & 4 & 3,28 & 8 & 6,55 \\
\hline Total & 128 & 100 & 101 & 100 & 83 & 100 & 122 & 100 & 122 & 100 \\
\hline
\end{tabular}

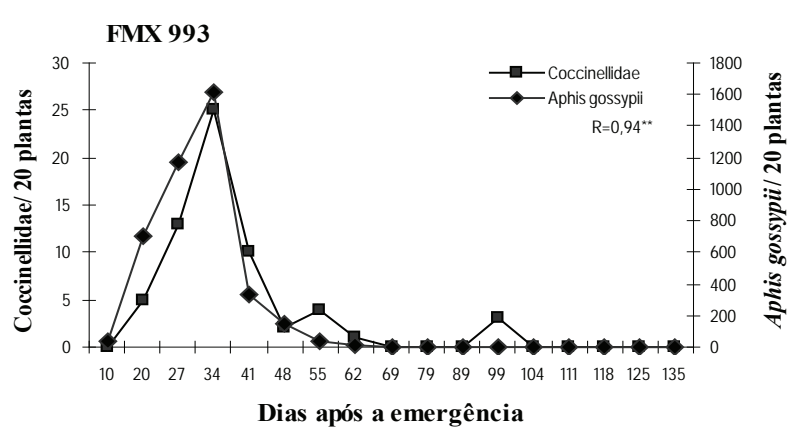

das diferenças entre estas cultivares, em relação à ocorrência de pulgões (196,47 e 102,59 indivíduos, respectivamente, em todo o período amostrado).

Abundância de artrópodes predadores por avaliação

Considerando-se os artrópodes predadores observados nas diferentes fases fenológicas da cul-
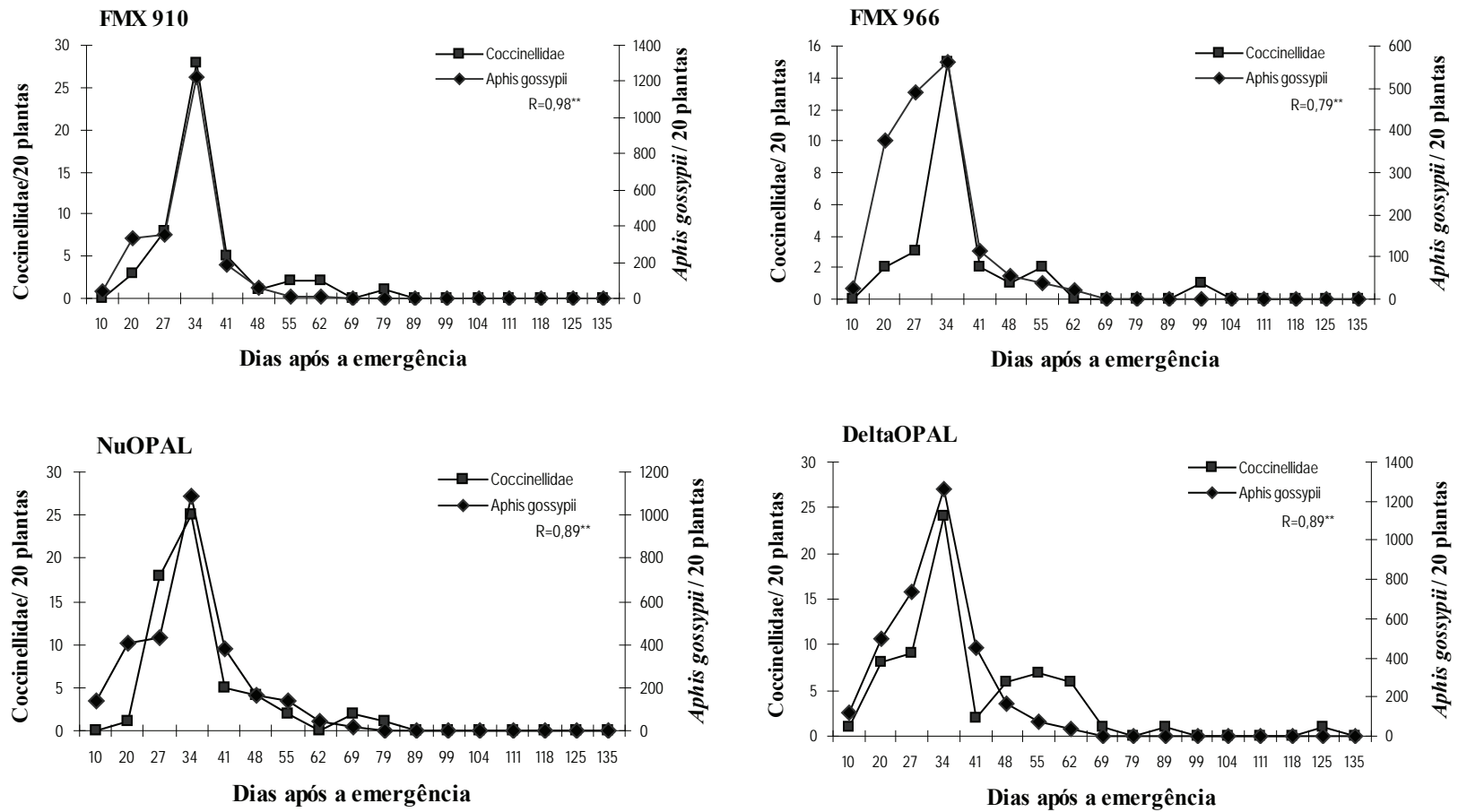

Figura 1. Dinâmica populacional de coccinelídeos e de Aphis gossypii nas cultivares de algodoeiro (Ipameri, GO, 2007/2008). 
Tabela 2. Média da ocorrência de artrópodes predadores e de pulgões observados nas cultivares de algodoeiro (Ipameri, GO, 2007/2008).

\begin{tabular}{lcccccccc}
\hline Cultivares & Araneae & $\begin{array}{c}\text { Coccinelidae } \\
\text { (adulto) }\end{array}$ & $\begin{array}{c}\text { Coccinelidae } \\
\text { (larva) }\end{array}$ & $\begin{array}{c}\text { Chrysopidae } \\
\text { (larva) }\end{array}$ & Forficulidae & Pentatomidae & Reduviidae & Pulgões \\
\cline { 2 - 9 } & $2,88 \mathrm{a}^{1}$ & $1,24 \mathrm{ab}$ & $2,47 \mathrm{a}$ & $0,18 \mathrm{a}$ & $0,35 \mathrm{a}$ & $0,41 \mathrm{a}$ & $0,00 \mathrm{a}$ & $238,24 \mathrm{ab}$ \\
FMX 993 & $2,06 \mathrm{a}$ & $0,76 \mathrm{ab}$ & $2,18 \mathrm{a}$ & $0,00 \mathrm{a}$ & $0,53 \mathrm{a}$ & $0,35 \mathrm{a}$ & $0,06 \mathrm{a}$ & $130,53 \mathrm{~b}$ \\
FMX 910 & $2,24 \mathrm{a}$ & $0,41 \mathrm{~b}$ & $1,12 \mathrm{a}$ & $0,18 \mathrm{a}$ & $0,29 \mathrm{a}$ & $0,35 \mathrm{a}$ & $0,29 \mathrm{a}$ & $102,59 \mathrm{~b}$ \\
NuOPAL & $2,41 \mathrm{a}$ & $1,00 \mathrm{ab}$ & $2,41 \mathrm{a}$ & $0,12 \mathrm{a}$ & $1,00 \mathrm{a}$ & $0,00 \mathrm{a}$ & $0,24 \mathrm{a}$ & $165,29 \mathrm{a}$ \\
DeltaOPAL & $2,00 \mathrm{a}$ & $1,59 \mathrm{a}$ & $2,29 \mathrm{a}$ & $0,12 \mathrm{a}$ & $0,53 \mathrm{a}$ & $0,18 \mathrm{a}$ & $0,47 \mathrm{a}$ & $196,47 \mathrm{a}$ \\
\hline F & $0,53^{\mathrm{ns}}$ & $2,43^{* *}$ & $2,52^{\mathrm{ns}}$ & $0,54^{\mathrm{ns}}$ & $1,56^{\mathrm{ns}}$ & $0,65^{\mathrm{ns}}$ & $1,62^{\mathrm{ns}}$ & $5,02 * *$ \\
CV (\%) & 12,59 & 8,90 & 6,95 & 4,40 & 8,46 & 8,12 & 6,05 & $11,35 * *$ \\
\hline
\end{tabular}

${ }^{1}$ médias seguidas por letras distintas, na coluna, diferem, estatisticamente, entre si, pelo teste Tukey, a $5 \%$; ** teste $\mathrm{F}$ significativo a $1 \%$; ${ }^{\text {ns }}$ não significativo.

tura do algodoeiro, verificou-se que os Coccinellidae (larvas e adultos), com 263 indivíduos (47,3\%), e as aranhas, com 197 indivíduos (35,4\%), foram os mais abundantes (Tabela 3).

Os resultados do presente estudo assemelham-se aos encontrados por Barros et al. (2006) e Sujii et al. (2007), que verificaram, na região de Dourados (MS) e do Distrito Federal, que a família de predadores predominante foi Coccinellidae. Prasifka et al. (1999) também verificaram, no Texas (EUA), que os coccinelídeos e as aranhas geralmente são os predadores mais abundantes na cultura do algodoeiro.

A maior abundância destes predadores, em relação aos demais, ocorre porque a maioria das espécies de coccinelídeos, tanto larvas como adultos, apresentam grande diversidade de presas, alimentando-se não apenas de pulgões, mas, também, de ácaros e lepidópteros (ovos e lagartas pequenas) (Iperti 1999). Já as aranhas são altamente generalistas e, portanto, capazes de se alimentar de várias pragas, incluindo adultos da maioria dos insetos, que normalmente escapam ao controle exercido por outros predadores e parasitóides importantes (Withcomb 1980).

As aranhas foram observadas em todo o ciclo do algodoeiro e os coccinelídeos ocorreram em maior densidade populacional no início do desenvolvimento da cultura (Tabela 3), quando, também, se verificou o período de maior ocorrência de $A$. gossypii. Trabalhos realizados por Barros et al. (2006) e Ramiro \& Farias (2006) comprovaram maior abundância de

Tabela 3. Número total de artrópodes predadores e afídeos observados na cultura do algodoeiro, em cada avaliação (Ipameri, GO, 2007/2008).

\begin{tabular}{|c|c|c|c|c|c|c|c|c|}
\hline $\mathrm{DAE}^{1}$ & Araneae & $\begin{array}{l}\text { Coccinellidae } \\
\text { (adulto) }\end{array}$ & $\begin{array}{c}\text { Coccinellidae } \\
\text { (larva) }\end{array}$ & $\begin{array}{c}\text { Chrysopidae } \\
\text { (larva) }\end{array}$ & Forficulidae & Pentatomidae & Reduviidae & Aphididae \\
\hline 10 & 4 & 1 & 0 & 0 & 0 & 0 & 0 & 361 \\
\hline 20 & 13 & 9 & 10 & 0 & 0 & 0 & 0 & 2327 \\
\hline 27 & 19 & 7 & 44 & 0 & 1 & 0 & 0 & 3189 \\
\hline 34 & 17 & 15 & 102 & 2 & 0 & 0 & 4 & 5742 \\
\hline 41 & 7 & 10 & 14 & 1 & 1 & 0 & 1 & 1455 \\
\hline 48 & 16 & 10 & 4 & 2 & 0 & 0 & 0 & 598 \\
\hline 55 & 12 & 15 & 2 & 0 & 1 & 0 & 2 & 295 \\
\hline 62 & 9 & 9 & 0 & 1 & 5 & 0 & 1 & 117 \\
\hline 69 & 10 & 3 & 0 & 0 & 2 & 0 & 3 & 16 \\
\hline 79 & 11 & 2 & 0 & 0 & 2 & 0 & 0 & 0 \\
\hline 89 & 15 & 1 & 0 & 1 & 1 & 0 & 2 & 0 \\
\hline 99 & 17 & 3 & 1 & 0 & 4 & 2 & 1 & 0 \\
\hline 104 & 7 & 0 & 0 & 1 & 5 & 1 & 3 & 0 \\
\hline 111 & 8 & 0 & 0 & 1 & 5 & 3 & 0 & 0 \\
\hline 118 & 12 & 0 & 0 & 0 & 9 & 7 & 0 & 0 \\
\hline 125 & 9 & 0 & 1 & 0 & 5 & 7 & 0 & 0 \\
\hline 135 & 11 & 0 & 0 & 1 & 5 & 2 & 1 & 0 \\
\hline Total & 197 & 85 & 178 & 10 & 46 & 22 & 18 & 14100 \\
\hline
\end{tabular}

${ }^{1}$ DAE: dias após a emergência das plantas. 
coccinelídeos predadores associados a populações do pulgão $A$. gossypii, demonstrando a distribuição destes predadores nas regiões produtoras de algodão.

Os pentatomídeos, representados pelo gênero Podisus, e os forficulídeos, pelo gênero Doru (tesourinhas), predominaram dos $99 \mathrm{DAE}$ aos $135 \mathrm{DAE}$ (Tabela 3), coincidindo com o período de maior população de pragas-alvo destes insetos, como, por exemplo, Alabama argillacea (Lepidoptera: Noctuidae). Este resultado corrobora os obtidos por Silva et al. (1995) e Barros et al. (2006), que verificaram acréscimo populacional de Podisus spp. no final do ciclo do algodoeiro, coincidindo com a maior ocorrência de $A$. argillacea.

De acordo com Barros et al. (2006), a ocorrência de determinado grupo de predadores está relacionada com as espécies de insetos-praga predominantes em determinada fase de desenvolvimento da cultura.

Os reduviídeos, representados pelo gênero Zellus, e as larvas de crisopídeos apresentaram menor abundância, em relação às demais famílias de predadores encontradas, sendo observados a partir dos $34 \mathrm{DAE}$ (Tabela 3). Estes resultados estão de acordo com Barros et al. (2006), que verificaram que, apesar da importância destes predadores no controle de pragas do algodoeiro, eles ocorrem em baixa densidade populacional, quando comparados a outros predadores.

\section{Dinâmica populacional de coccinelídeos e pulgões}

Houve predominância de coccinelídeos (larvas e adultos), até $55 \mathrm{DAE}$, em todas as cultivares, apresentando pico populacional aos 34 DAE (Tabela $3 \mathrm{e}$ Figura 1), coincidindo com o pico populacional de A. gossypii, também observado aos $34 \mathrm{DAE}$, em todas as cultivares (Figura 1). Resultados semelhantes foram relatados por Barros et al. (2006), que verificaram que a flutuação populacional de coccinelídeos acompanhava a flutuação de $A$. gossypii no algodoeiro, com picos ocorrendo entre 30 DAE e 40 DAE.
A população de pulgões no algodoeiro, em condições favoráveis, é bastante elevada, principalmente quando não são feitas pulverizações com inseticidas. Desta forma, é de se esperar que a população de coccinelídeos, predadores mais diretamente relacionados àquela praga, apresente picos populacionais, quando há maior ocorrência de pulgões.

Os adultos de coccinelídeos observados na área foram Cycloneda sanguinea, Eriopis connexa e Scymnus spp., sendo que E. connexa foi a espécie mais abundante durante o ciclo do algodoeiro, em todas as cultivares (Tabela 4). Entretanto, considerando-se as formas imaturas, Scymnus spp. foi o mais abundante, em todas as cultivares estudadas (Tabela 4). Este resultado corrobora os observados por Campos et al. (1986), Soares \& Busoli (1995), Michelotto et al. (2003) e Barros et al. (2006), que verificaram que o gênero Scymnus spp. apresentou maior número de indivíduos, em relação aos demais insetos benéficos.

Interações entre predadores/predadores e predadores/fatores meteorológicos

Em relação à interação entre as populações de predadores, observou-se que as aranhas apresentaram correlação positiva e significativa com Coccinellidae (adulto e larva), Chrysopidae (larva) e Reduviidae. Os coccinelídeos adultos, além de apresentarem correlação com as aranhas, também se correlacionaram positivamente com as larvas de coccinelídeos e crisopídeos, o mesmo ocorrendo entre os forficulídeos e os pentatomídeos (Tabela 5).

Estes resultados sugerem que não houve interferência negativa entre os predadores, isto é, provavelmente, estes grupos não competiram entre si por presas. Entretanto, Cisneros \& Rosenheim (1997), trabalhando com Zellus renardii e crisopídeos, relataram que pode ocorrer interação negativa

Tabela 4. Percentagem de ocorrência de espécies/gêneros de coccinelídeos por cultivar, na cultura do algodoeiro (Ipameri, GO, 2007/2008).

\begin{tabular}{lrrrrr}
\hline \multirow{2}{*}{ TAXA } & \multicolumn{3}{c}{ Cultivares (\%) } \\
\cline { 2 - 6 } & FMX 993 & FMX 966 & FMX 910 & DeltaOPAL & NuOPAL \\
\hline Adulto de C. sanguinea & 6,56 & 3,85 & 5,77 & 6,45 & 5,00 \\
Adulto de E. conexa. & 24,59 & 19,23 & 19,23 & 22,58 & 13,33 \\
Adulto de Scymnus spp. & 3,28 & 3,85 & 1,92 & 9,68 & 8,33 \\
Larvas de Scymnus spp. & 44,26 & 42,31 & 48,08 & 40,32 & 56,67 \\
Larvas de Cycloneda spp. e Eriopis spp. & 21,31 & 30,76 & 25,00 & 20,97 & 16,67 \\
\hline
\end{tabular}


Tabela 5. Coeficientes de correlação linear simples entre os artrópodes predadores, na cultura do algodoeiro (Ipameri, GO, 2007/2008).

\begin{tabular}{lcccccc}
\hline \multicolumn{1}{c}{ Artrópodes } & Araneae & $\begin{array}{c}\text { Coccinellidae } \\
\text { (adulto) }\end{array}$ & $\begin{array}{c}\text { Coccinellidae } \\
\text { (larva) }\end{array}$ & $\begin{array}{c}\text { Chrysopidae } \\
\text { (larva) }\end{array}$ & Forficulidae & Pentatomidae \\
\hline Araneae & - & - & - & - & - & - \\
Coccinellidae (adulto) & $0,6527^{*}$ & - & - & - & - & - \\
Coccinellidae (larva) & $0,6661^{*}$ & $0,6012^{*}$ & - & - & - & - \\
Chrysopidae (larva) & $0,7973^{* *}$ & $0,7564^{* *}$ & $0,5382^{\mathrm{ns}}$ & - & - & - \\
Forficulidae & $0,1747^{\mathrm{ns}}$ & $-0,3787^{\mathrm{ns}}$ & $-0,2202^{\mathrm{ns}}$ & $0,0922^{\mathrm{ns}}$ & - & - \\
Pentatomidae & $0,0703^{\mathrm{ns}}$ & $-0,4220^{\mathrm{ns}}$ & $-0,1862^{\mathrm{ns}}$ & $-0,0716^{\mathrm{ns}}$ & $0,8488^{* *}$ & - \\
Reduviidae & $0,6564^{*}$ & $0,4079^{\mathrm{ns}}$ & $0,5058^{\mathrm{ns}}$ & $0,5590^{\mathrm{ns}}$ & $-0,0285^{\mathrm{ns}}$ & $-0,2820^{\mathrm{ns}}$ \\
\hline
\end{tabular}

* significativo a $5 \%$; ** significativo a $1 \%$; ${ }^{\text {ns }}$ não significativo.

Tabela 6. Coeficientes de correlação linear simples, entre os fatores meteorológicos e a ocorrência de artrópodes predadores, na cultura do algodoeiro (Ipameri, GO, 2007/2008).

\begin{tabular}{lccc}
\hline \multicolumn{1}{c}{ Artrópodes } & $\begin{array}{c}\text { Temperatura } \\
\text { máxima }\end{array}$ & $\begin{array}{c}\text { Temperatura } \\
\text { mínima }\end{array}$ & $\begin{array}{c}\text { Precipitação } \\
\text { pluvial }\end{array}$ \\
\hline Araneae & $-0,2052^{\mathrm{ns}}$ & $0,0965^{\mathrm{ns}}$ & $0,0575^{\mathrm{ns}}$ \\
Coccinellidae (adulto) & $-0,2677^{\mathrm{ns}}$ & $0,4099^{\mathrm{ns}}$ & $0,2345^{\mathrm{ns}}$ \\
Coccinellidae (larva) & $-0,3035^{\mathrm{ns}}$ & $0,2599^{\mathrm{ns}}$ & $-0,0133^{\mathrm{ns}}$ \\
Chrysopidae (larva) & $-0,4227^{\mathrm{ns}}$ & $0,1996^{\mathrm{ns}}$ & $0,3220^{\mathrm{ns}}$ \\
Forficulidae & $0,2468^{\mathrm{ns}}$ & $-0,0344^{\mathrm{ns}}$ & $-0,4056^{\mathrm{ns}}$ \\
Pentatomidae & $0,2120^{\mathrm{ns}}$ & $-0,0238^{\mathrm{ns}}$ & $-0,4554^{\mathrm{ns}}$ \\
Reduviidae & $-0,3558^{\mathrm{ns}}$ & $-0,1090^{\mathrm{ns}}$ & $0,3478^{\mathrm{ns}}$ \\
\hline${ }^{\mathrm{ns}}$ não significativo. & & &
\end{tabular}

entre predadores, causando aumento na densidade populacional do pulgão $A$. gossypii.

Vários são os fatores bióticos e abióticos que podem influenciar na ocorrência de artrópodes predadores no campo e, consequentemente, interferir no controle biológico (Symondson et al. 2002). Entretanto, neste estudo, os fatores meteorológicos analisados não apresentaram correlação significativa com a população de predadores (Tabela 6).

\section{CONCLUSÕES}

1. O número total de artrópodes predadores é semelhante nas cultivares estudadas, sendo Coccinellidae a família predominante.

2. Os coccinelídeos e os pulgões apresentam flutuações populacionais semelhantes, com maior pico populacional aos 34 dias após a emergência das plantas.

3. Aranhas são predadores generalistas e ocorrem durante todo o ciclo da cultura.
4. Pentatomídeos e forficulídeos ocorrem no final do ciclo, coincidindo com a maior população de pragas-alvo destes insetos.

5. Não ocorre interação negativa entre os grupos de predadores.

6. Não há influência dos fatores meteorológicos sobre as populações de artrópodes predadores.

\section{AGRADECIMENTOS}

Ao Conselho Nacional de Desenvolvimento Científico e Tecnológico $(\mathrm{CNPq})$ e à Fundação de Amparo à Pesquisa do Estado de São Paulo (FAPESP), pela concessão de bolsa aos autores.

\section{REFERÊNCIAS}

ALVES, A. P.; SERIKAWA, R. H. Controle químico de pragas do algodoeiro. Revista Brasileira de Oleaginosas e Fibrosas, Campina Grande, v. 10, n. 3, p. 1197-1290, 2006.

BARROS, R. et al. Flutuação populacional de insetos predadores associados a pragas do algodoeiro. Arquivos do Instituto Biológico, São Paulo, v. 73, n. 1, p. 57-64, 2006.

BUSOLI, A. C.; MICHELOTTO, M. D; ROCHA, K. C. G. Controle biológico de pragas no MIP-algodoeiro no Cerrado brasileiro. In: DE BORTOLI, S. A.; BOIÇA JÚNIOR, A. L.; OLIVEIRA, J. E. M. (Eds.). Agentes de controle biológico: metodologias de criação, multiplicação e uso. Jaboticabal: Funep, 2006. p. 331-353.

CAMPOS, R. A. et al. Artrópodes predadores na cultura algodoeira e comparação de métodos de amostragem. Anais da Sociedade Entomológica do Brasil, Londrina, v. 15, supl., p. 5-20, 1986.

CISNEROS, J. J.; ROSENHEIM, J. A. Ontogenetic change of prey preference in the generalist predator Zellus renardii and its influence on predator-predator interactions. Ecological Entomology, London, v. 22, n. 4, p. 399-407, 1997. 
COMPANHIA NACIONAL DE ABASTECIMENTO (Conab). Avaliação da safra agrícola 2008/2009. Brasília, DF: Conab, 2009.

COSTA, R. I. F. et al. Consumo de Bemisia argentifolii (Bellows \& Perring) (Hemiptera: Aleyrodidae) e Aphis gossypii (Glover, 1877) (Homoptera: Aphididae) por Chrysoperla externa (Hagen, 1861) (Neuroptera: Chrysopidae). In: CONGRESSO BASILEIRO DE ALGODÃO, 2., 1999, Ribeirão Preto. Resumos... Campina Grande: Embrapa algodão, 1999. p. 256-258.

DEGRANDE, P. E. et al. Avaliação de métodos para quantificar predadores de pragas do algodoeiro. Arquivos do Instituto Biológico, São Paulo, v. 70, n. 3, p. 291-294, 2003.

EUBANKS, M. D.; DENNO, R. F. Health food versus fast food: the effects of prey quality and mobility on prey selection by a generalist predator and indirect interactions among prey species. Ecological Entomology, London, v. 25, n. 2, p. 140-146, 2001.

FERNANDES, M. G.; BUSOLI, A. C.; BARBOSA, J. C. Distribuição espacial de Alabama argillacea (Hubner) (Lepidoptera: Noctuidae) em algodoeiro. Neotropical Entomology, Londrina, v. 32, n. 1, p. 107-115, 2003.

FITT, G. P. Cotton pest management: part 3. An Australian perspective. Annual Review of Entomology, Palo Alto, v. 39, n. 3, p. 543-562, 1994.

FREIRE, E. C. et al. Redução nos custos de produção do algodão obtidos com uso de cultivares resistentes a viroses no Cerrado. In: CONGRESSO BRASILEIRO DE ALGODÃO, 2., 1999, Ribeirão Preto. Anais... Campina Grande: Embrapa Algodão, 1999. p. 1-3.

GRAVENA, S.; CUNHA, H. F. Artrópodes predadores na cultura algodoeira. Jaboticabal: CEMIP/Departamento de Entomologia e Nematologia, 1991. (Boletim, 1).

GRAVENA, S.; STERLING, W. L. Natural predation on the cotton leafworm (Lepidoptera: Noctuidae). Journal of Economic Entomology, Lanham, v. 76, n. 4, p. 779-784, 1983.

IPERTI, G. Biodiversity of predaceous Coccinellidae in relation to bioindication and economic importance. Agriculture, Ecosystems and Environment, Amsterdam, v. 74, n. 1-3, p. 323-342, 1999.

LUTTRELL, R. G. et al. Cotton pest management: part 1. A worldwide perspective. Annual Review of Entomology, Palo Alto, v. 39, n. 3, p. 517-526, 1994.

MICHELOTTO, M. D. et al. Diversidade e abundância de coccinelídeos em seis cultivares de algodoeiro (Gossypium hirsutum L.). Boletín de Sanidad Vegetal Plagas, Madrid, v. 29, n. 2, p. 219-226, 2003.

OBRYCKI, J. J.; KRING, T. J. Predaceous Coccinellidae in biological control. Annual Review of Entomology, Palo Alto, v. 43, n. 2, p. 295-321, 1998.

OLIVEIRA, E. E. et al. Aspectos biológicos do predador Cycloneda sanguinea (Coleoptera, Coccinellidae) alimentado com Tetranychus evansi (Acari, Tetranychidae) e Macrosiphum euphorbiae (Homoptera, Aphididae). Bioscience Journal, Uberlândia, v. 21, n. 2, p. 33-39, 2005.
OLIVEIRA, J. E. M. et al. Biologia de Podisus nigrispinus predando lagartas de Alabama argillacea em campo. Pesquisa Agropecuária Brasileira, Brasília, DF, v. 37, n. 1, p. 7-14, 2002.

OLIVEIRA, J. E. M. et al. Predação de lagartas de Alabama argillacea por ninfas e adultos de Podisus nigrispinus sob efeito de diferentes tamanhos de presa. In: CONGRESSO BRASILEIRO DE ALGODÃO, 3., 2001, Campo Grande. Resumos... Campina Grande: Embrapa Algodão, 2001. p. 382-385.

PEREIRA, M. J. B.; ALBUQUERQUE, F. A.; BASTOS, C. S. Pragas do algodoeiro: identificação, biologia e sintomas de ataque. Revista Brasileira de Oleaginosas e Fibrosas, Campina Grande, v. 10, n. 3, p. 1073-1117, 2006.

PRASIFKA, J. R. et al. Predator conservation in cotton: using grain sorghum as a source for insect predators. Biological Control, San Diego, v. 16, n. 2, p. 223-229, 1999.

RAMIRO, Z. A.; FARIAS, A. M. de. Levantamento de insetos predadores nas cultivares de algodão bollgard Dp 90 e convencional delta pine acala 90. Arquivos do Instituto Biológico, São Paulo, v. 73, n. 1, p. 119-121, 2006.

SARMENTO, R. A. et al. Functional response of the predator Eriopis connexa (Coleoptera: Coccinellidae) to different prey types. Brazilian Archives of Biology and Technology, Curitiba, v. 50, n. 1, p. 121-126, 2007.

SILVA, A. L. et al. Inimigos naturais de Alabama argillacea (Hueb.) em regiões cotonicultoras do Estado de Goiás. Anais das Escolas de Agronomia e Veterinária, Goiânia, v. 25, n. 2, p. 141-147, 1995.

SILVIE, P. et al. Manual de identificação dos inimigos naturais no cultivo do algodão. Cascavel: CODETEC/ CIRAD, 2001. (Boletim Técnico, 5).

SOARES, J. J.; BUSOLI, A. C. Comparação entre métodos de amostragem para artrópodes predadores associados ao algodoeiro. Anais da Sociedade Entomológica do Brasil, Londrina, v. 24, n. 3, p. 551-556, 1995.

SOUSA, D. M. G. de; LOBATO, E. Calagem e adubação para culturas anuais e semiperenes. In: SOUSA, D. M. G. de; LOBATO, E. (Eds.). Cerrado: correção do solo e adubação. 2. ed. Brasília, DF: Embrapa Informação Tecnológica, 2004. p. 283-315.

SUJII, E. R. et al. Comunidade de inimigos naturais e controle biológico do pulgão, Aphis gossypii Glover (Hemiptera: Aphididae) e do curuquerê, Alabama argillacea Hübner (Lepidoptera: Noctuidae) na cultura do algodoeiro no Distrito Federal. Arquivos do Insituto Biológico, São Paulo, v. 74, n. 4, p. 329-336, 2007.

SYMONDSON, W. O. C.; SUNDERLAND, K. D.; GREENSTONE, M. H. Can generalist predators be effective biocontrol agents? Annual Review of Entomology, Palo Alto, v. 47, n. 1, p. 561-594, 2002.

WITHCOMB, W. H. Sampling spiders on soybean fields. In: KOGAN, M.; HERZOG, D. C. (Eds.). Sampling methods in soybean entomology. New York: SpringerVerlag, 1980. p. 544-557. 